\title{
في المراكز القانونية لسلطات الضبط المستقلة:السلطة الوطنية التقنية النباتية
}

In the legal centers of independent control authorities: the National

Technical Plant Authority

تاريخ الاستلام :2019/05/06؛ تاريخ القبول :30/05/T2

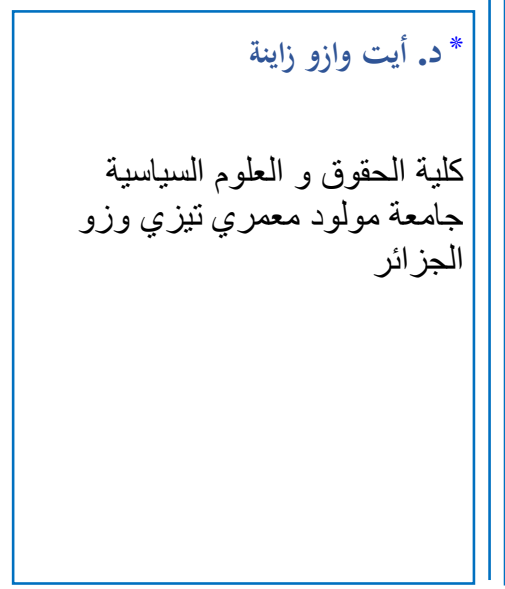

\section{Abstract}

In the 1990s, public authorities in Algeria introduced a new administrative entity to regulate the economy, a practice reserved, so far, to the executive power. However, to cope with the demands of fast economic development, a new policy of regulation and governance is needed. Various entities, known as independent regulatory authorities, have been established by law, playing different roles according to their relevant sector. Their statuses are so distinct, that they call for some reflections in the field.

Keywords: executive power; administrative entity to regulate ;regulation ;independence ;regulatory authorities.

\section{Résumé}

Depuis les années 90, les autorités publiques ont introduit dans le paysage de l'Etat une nouvelle catégorie administrative chargée de jouer le rôle de régulateur en matière économique, champs de compétence réservé jusqu'à présent au pouvoir exécutif. Mais, face aux nouvelles exigences du développement rapide du secteur économique, une nouvelle politique de régulation et de gouvernance s'impose. Diverses institutions /autorités, dites autorités de régulation indépendantes, ont été créées en vertu de la loi, leur octroyant des rôles différents en fonction des secteurs de compétences. Leurs statuts s'avèrent distincts, ce qui suscite certaines réflexions à cet égard.

Mots clés: autorités de régulation ;autorité phytotechnique ;pouvoir executif ;indépendance ;régulation

* Corresponding author, e-mail: aitouazzouzaina@ yahoo.fr 
أمام تطور النشاط الاقتصادي وتشعب مجالاته وتعقيدها، أصبحت الدولة عاجزة

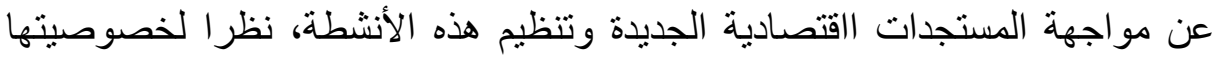


التنظيم في قطاعات معينة، الذي هو أصلا حكر للسلطة التنفيذية. وتتمثل هذه الهيئات في الهيئات الإدارية المستقلة أو ما يعرف بهيئات الضبط

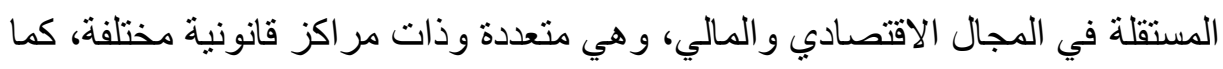

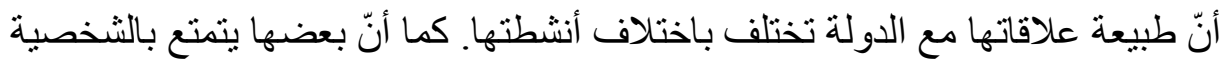

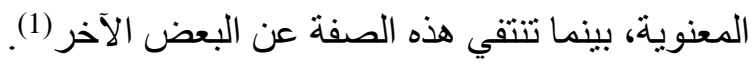
إنّ هذا التعدد في المر اكز القانونية للهيئات الإدارية المستقلة وتتوع الأنشطة التي

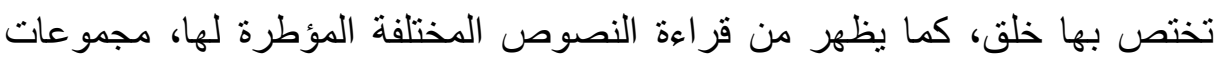
تندرج فيها هه الهيئات ونميز بين مجمو عنين أساسيتين في تقسيم هذه الهيئات:

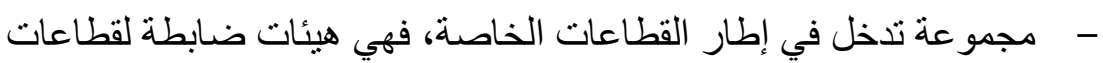



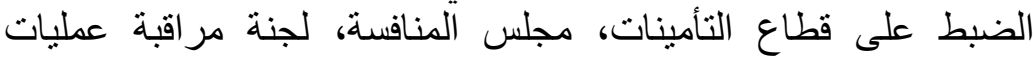
البورصة وكذا السلطة الوطنية التقنية النباتية التي هي محل بحثنا هذا.

ومجموعة ثانية تضم ما يعرف بالهيئات الحامية للحريات و الروابط الإئل

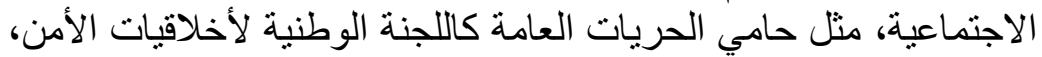

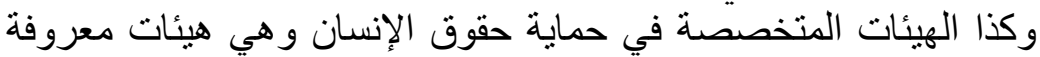

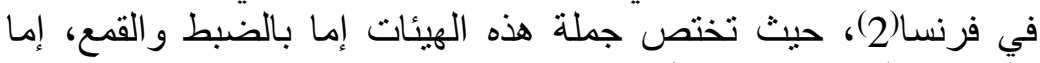

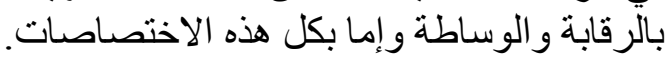

ترتبط هيئات الضبط المستقلة في معظمها بأجهزة عمومية تابعة للدولة، تعمل

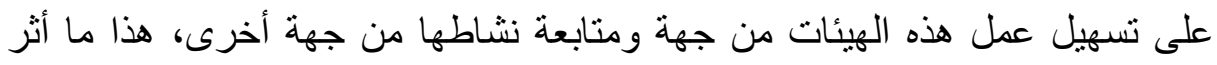

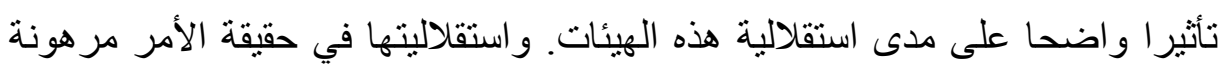

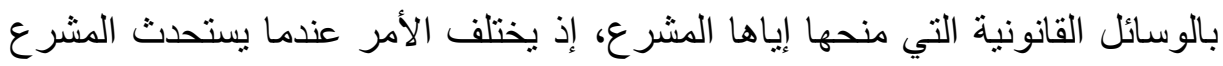


يجعلها في منأى عن رقابة أية هيئة وصية، أو عندما يستحدث سلطة ضبط دونة دون منحها

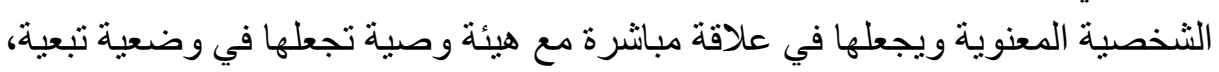

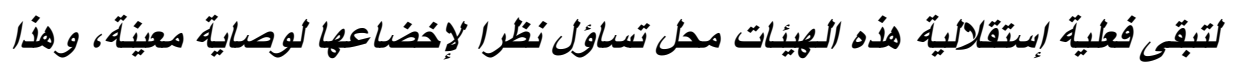


pyrotechnique 


\section{I}

استحدثت السلطة الوطنية التقنية النباتية بموجب القانون رقم 05-03 الصادر في 06 فيفري 2005، المتعلق بالبذور و الثتائل وحماية الحيازة النباتية، حيث تتص المادة 04 منه على أنّه تنشأ لدى الوزير المكلف بالفلاحة سلطة وطنية ولفية تقنية نباتية. كما نجد من خلال تفحص المادة 05 من القانون نفسه أنّ هذه السلطة تتكون من لجنة وطنية للبذور و الثتائل، تضم لجانا تقنية متخصصة ولفئ مفتشين تقنيين(4).

إنّ نص المادة نفسه يحيلنا إلى التتظيم لتحديد كيفيات تتظيم السلطة الوطنية

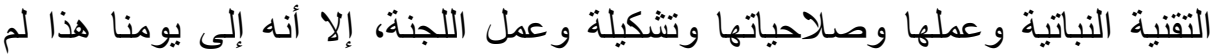
يصدر أي تتظيم بخصوص السلطة الوطنية التقنية النباتية، الأمر الذي يحول دون تحديد مركز ها القانوني ومدى تمتعها بالاستقلالية في أداء مهام، مما يجعل منها مجرّد امتداد لفرع من فروع الوز ارة المعنية بهذا القطاع.

فالمشرع يستعمل عدة تسميات لتكييفه هيئات جديدة أسندت لها مهام الضبط في قطاعات وأنشطة مختلفة، فمصطلح السلطة لا يعني بالتأكيد تلك السلطة المستقلة L'autorité indépendante إلى تكييف صحيح لمركز هذه السلطة الجديدة. ولعلنا سنذهب لا اعتناق هذا الرأي

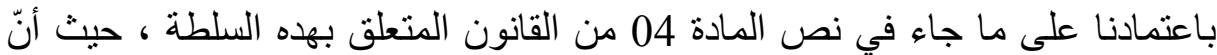
المشرع ذكر بصريح النص على أنّ هذه السلطة سلطة تنشأ لدى الوزير المكلف

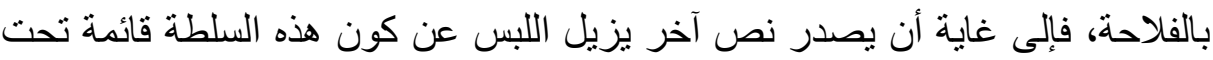

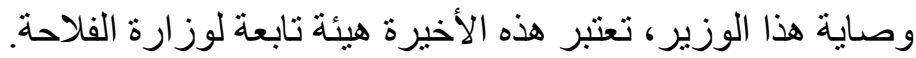
إنّ هذه السلطة على حد ما جاء في نص المادة 05 من القانون نفسه تتكون من اللجنة الوطنية للبذور و الثتائل و التي تضم بدور ها لجانا متخصصة، مع الاشارة الى ان

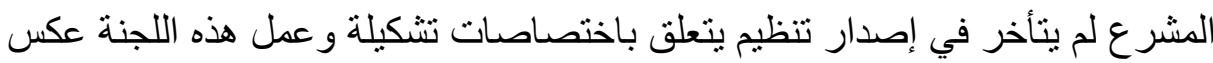
ما هو عليه الحال بخصوص السلطة الوطنية التقنية النباتية. و هنا يثار تساؤل نتيجة هذا الصموت أو الإغفال:

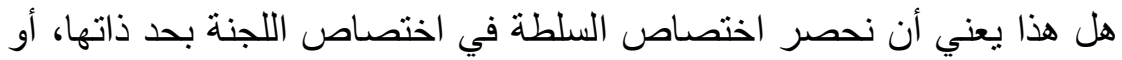

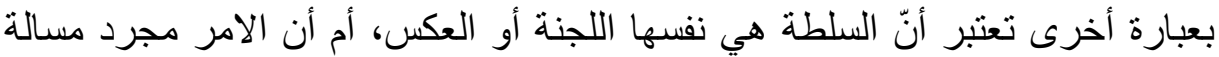



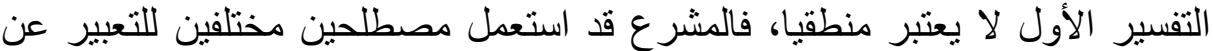
هيئتين، كما أنّه نص صر احة على أنّ السلطة الوطنية تتكون من لجنة معينة فينة. و عليه تعتبر اللجنة جهاز مكوّن لهذه السلطة.

إذا اعتمدنا على مختلف هذه المعطيات في البحث عن تكييف مركز السلطة

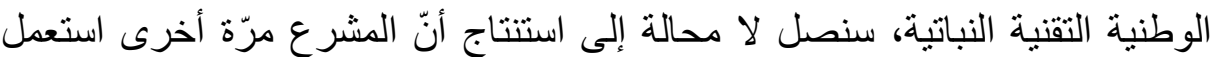
مصطلح السلطة، دون أن يقصد أو ينوي في ذلك منح الهيئة سلطة فعلية في أداء الاختصاص المنوط بها، بل هي تبقى تحت وصاية هيئة وصية تتمثل في الوزارة

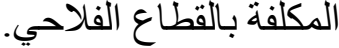


فالمشرع يستعمل عدة تسميات لتكييف هيئات جديدة مختصة بالضبط في عدة



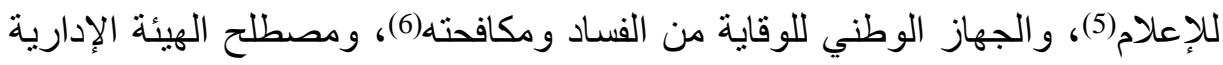

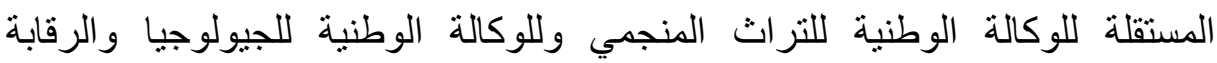
المنجمية(7). وسلطة ضبط المياه(8)، ومصطلح جهاز مستقل بالنسبة للجنة ضبط الكباء

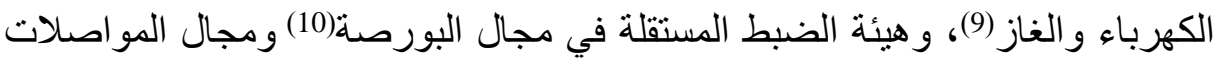
السلكية واللاسلكية(11)، ومصطلح مؤسسة لتكييف مجلس المناء المنافسة(12). فأصبح إذًا مفهوم المؤسسات الإدارية المستقلة أو هيئات الضبط المستقلة ومئة مجرد تعابير مختلفة،

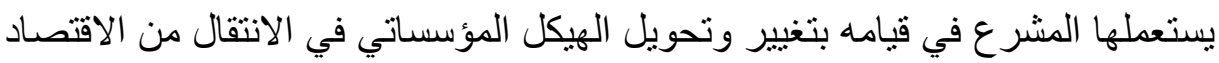

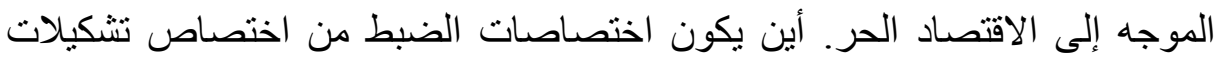
مأخوذة من نماذج هيئات الضبط المستقلة الغربية(13). بالرغم من عدم تعرض المشرع إلى تشكيلة السلطة الوطنية التقنية النباتية، إلا

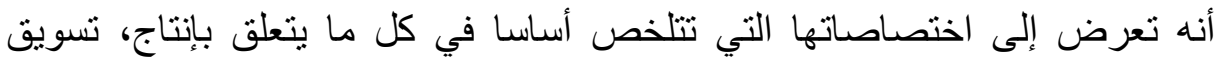

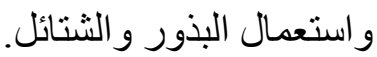

إذ أنّ هذه السلطة تختص بحصر وجمع قائمة القطع الأرضية المستعملة بهذا

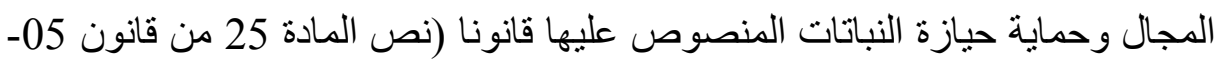



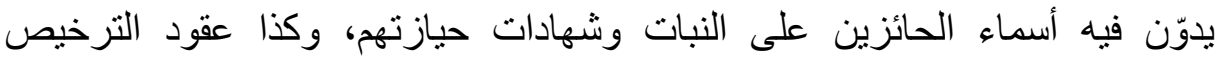
و الرخص الإجبارية والرخص التلقائية(15)، فهي المختصة في منح الاعتماد في هذات فئات المجال(16).

كما أنّ هذه السلطة تمارس رقابة على كل صاحب حق حيازة، حيث يتوجب

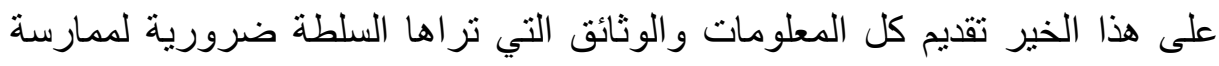
دور ها الرقابي.

وللإنشارة فإنّ الرخص التي تمنحها السلطة الوطنية التقنية النباتية عبارة عن

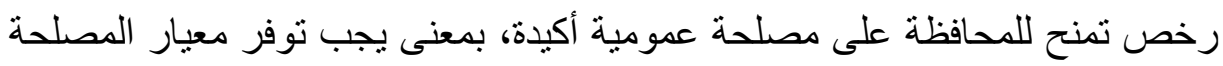

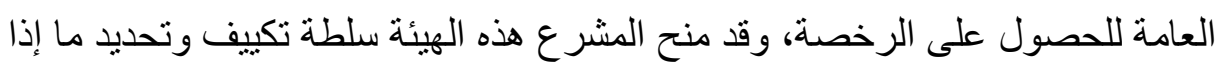

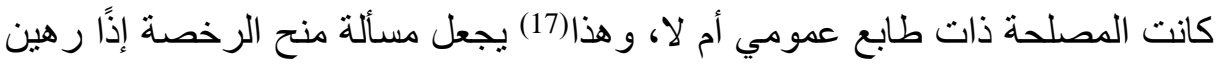

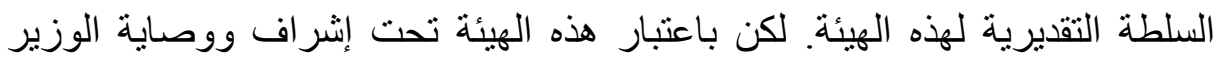


السلطة التقديرية للوزير المكلف بالفلاحة. وباعتبار أنّ السلطة الوطنية التقنية النباتية مؤهلة بممارسة دور رقابي على

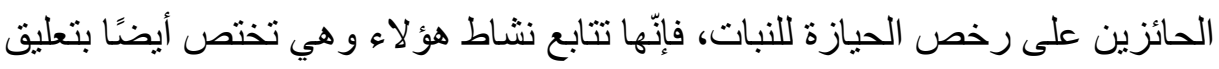


ضرورة استنفاذ كل طرق الطعن الإدارية والقضائية، وضرورة أن تتبت السلطة بأن 
الحق المتحصل عليه قد منح لشخص لم يكن له الحق في ذلك. إنّ هذا الشرط يضع في



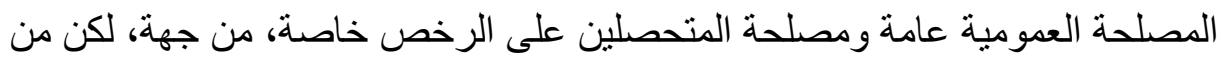
جهة أخرى، هذا الأمر يغل من السلطة التقديرية للهيئة وحريتها في ممارسة الرها

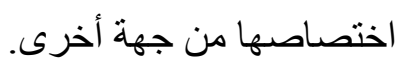
يمكن للأشخاص المعنية التي كانت موضوع رفوى رفض لطلباتها في استيراد أو تصدير أو تسويق البذور والثتائل أن ترفع طعنا في المسألة أمام السلطة الوطنية الوطنية التقنية

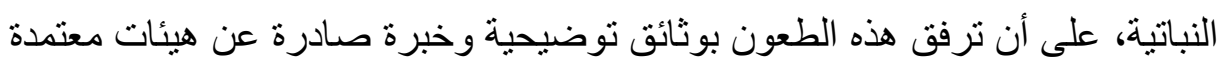

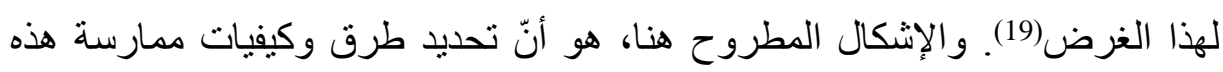



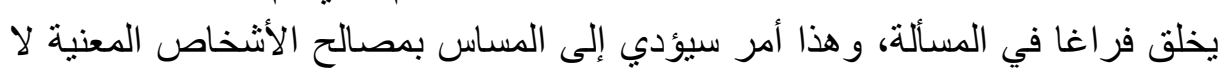

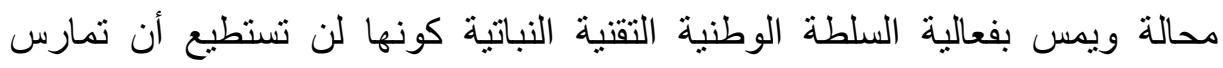

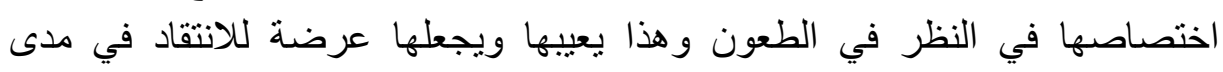
مصداقية وفعالية دور ها، لأنّ النظر في الطعن يستتبع بنتائج خطيرة من أهمها إمّا

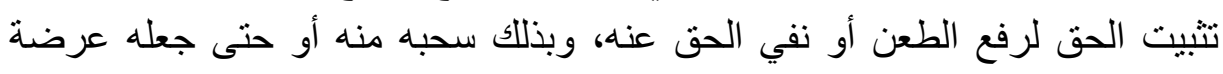

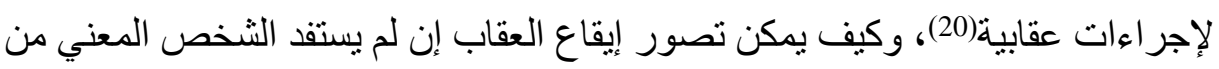



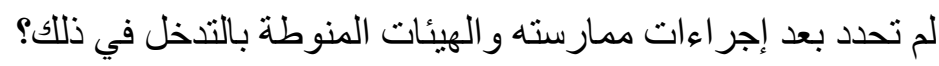
كما أنّه ومن الناحية العملية يمكن أن نتصور تدخل السلطة الوصية للنظر في

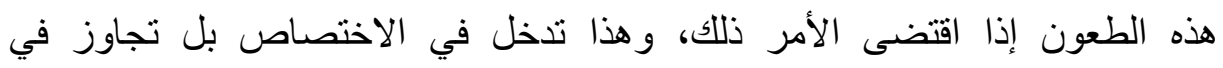
الاختصاص، بالنتيجة مساس باستقلالية الهيئة وتثبيت في تبعيتها.

إنّ فعالية ومصداقية مختلف الاختصاصات التي تمارسها هذه السلطة مرتبطة

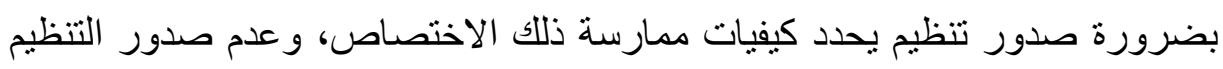

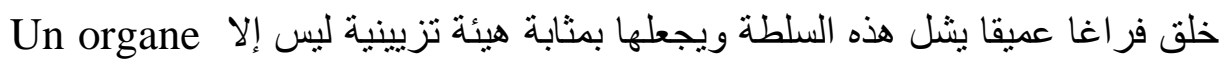
décoratif

إنّ كل هذه الملاحظات و الاستنتاجات المختلفة تجعلنا نجزم بانتفاء استقلالية هذه

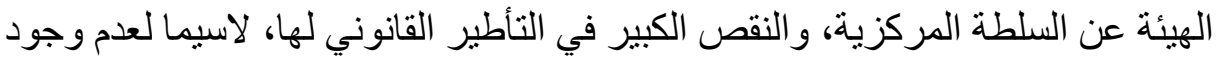

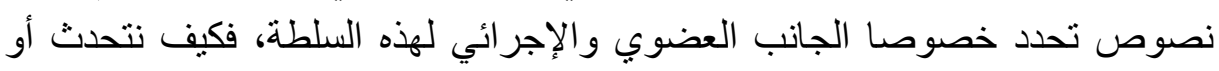
نناقش اختصاص أية هيئة في غياب تحديد صفة أعضاء الجهاز الممارسين

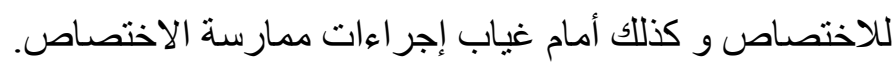

\section{- II}

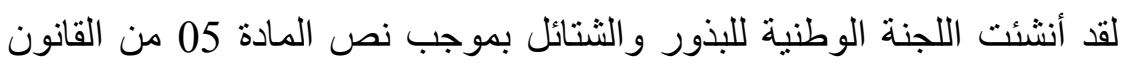

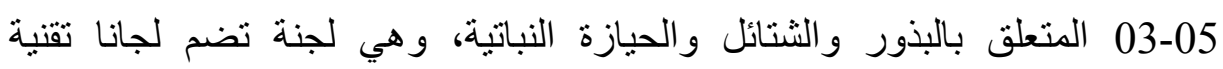
متخصصة ومفتتين تقنيين. وقد أحال المشرع مسألة تحديد تكوين هذه اللجنة واختصاصاتها للتنظيم، وعلى 
خلاف الأمر بالنسبة للسلطة الوطنية التقنية النباتية، فقد صدر مرسوم تنفيذي رقم 06246 مؤرخ في 09 جويلية 2006 يحدد اختصاصات تشكيلة وعمل اللجنة الوطنية للبذور و الثتائل(21) مؤن في

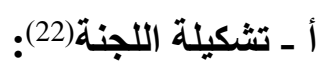

ـ تتشكل اللجنة من الوزير المكلف بالفلاحة وهو الذي ئهة أسها،

ـ مدير حماية النباتات و المر اقبات التقنية أو ممثلكه. ـ مدير الإنتاج الفلاحي وتنميته أو ممثله. ـ مدير التنظيم العقاري وحماية الأملاك أو ممثلكه. ـ مدير التكوين و البحث و الإرشاد أو ممثله. ـ المدير العام للمعهد التقني للمحاصيل الكبرى أو ممثله. ـ المدير العام للمعهد التقني لزر اعة البقول و المحاصيل الصناعية أو ممثلـ. ـ المدير العام للمعهد التقني للأشجار المثمرة و الكروم أو ممثله.


ـ المدير العام للمعهد الجز ائري للتقييس أو ممثلك. - رئيس الغرفة الوطنية للفلاحة أو ممثله.

- رؤساء المجالس الوطنية المهنية المشتركة المعنية أو ممثليهم. - رؤساء اللجان التقنية المتخصصة المذكورة فية في هذاء المرسوم نفسه. ـ ممثل الوزير المكلف بالتجارة. ـ ممثل الوزير المكلف بالتعليم العالي. ـ ممثل الوزير المكلف بالصناعة. ـ ممثل الوزير المكلف بالبيئة. ـ ممثل الوزير المكلف بالصحة.

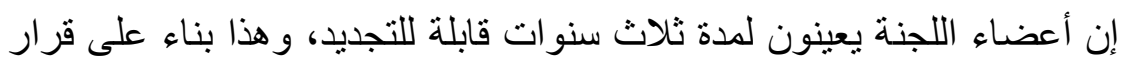

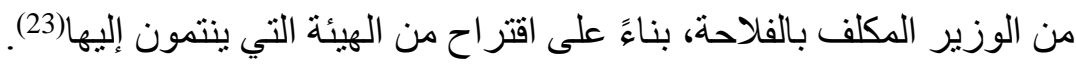
إنّ أداة التعيين هي القرار الوزاري الذي يصدره الوزير المكلف بالفلاحة، و عليه

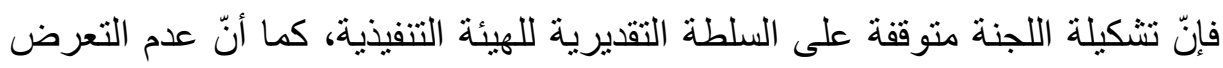

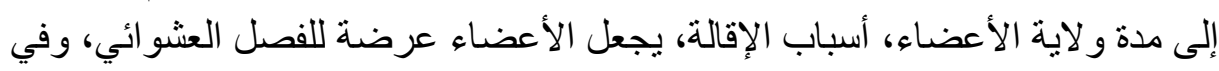

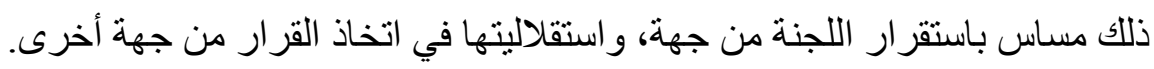
أضف إلى ذلك أنّه عندما يقرر النص بأنه الأعضاء المشكلون للجنة هم ممثلون

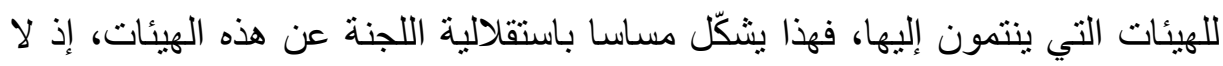

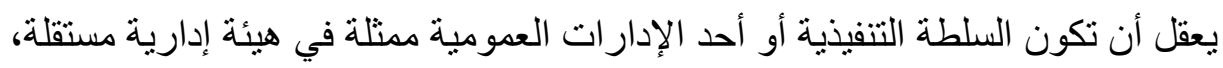

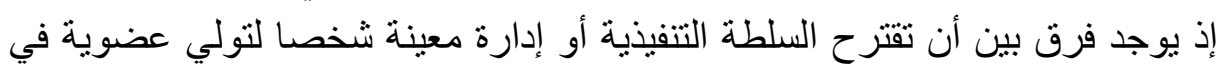

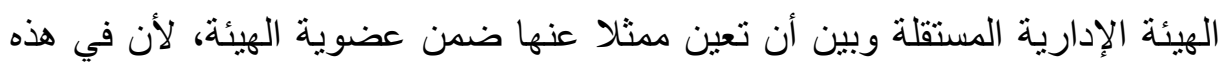
الحالة الأخيرة سيشكل تداخل وتدخل في اختصاصات الهيئة الإدارية المستقلة. 


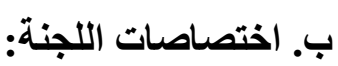

ـ تختص اللجنة الوطنية للبذور و الثتائل، طبقا لنص المادة 02 من المرسوم التتفيذي رقم 06-246 بعملية توجيه وتنسيق بر امج الإنتاج و التزويد بالبذور و الثنائل.

$$
\text { و هي منوطة بعدة اختصاصات مثل: }
$$



$$
\text { وترقية الإنتاج الوطني للبذور و الثتائل وتسويقها. }
$$



ـ در اسة طلبات حماية الحيازة النباتية.

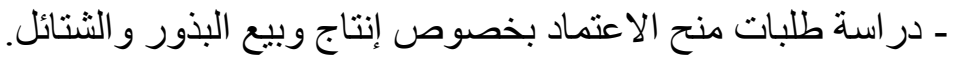
ـ در اسة الطلبات بخصوص التسجيل أو الثطب من السجل العمومي.

نلاحظ أن اختصاصات اللجنة شبيهة باختصاصات أمانة (سكريتاريا)، بل تكيفه

اللجنة على أنها تلعب دور أمانة السلطة الوطنية التقنية النباتية.

إنّ اللجنة تجتمع بناء على قرار من رئيسها المتمنت في الوزير المكلف بالفلاحة،

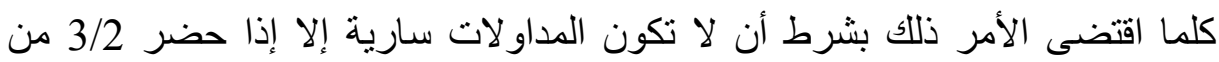

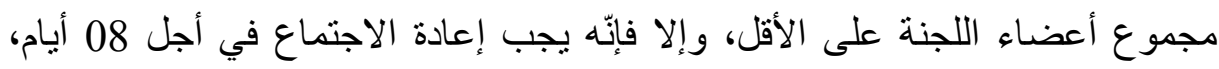
وهنا لا ينظر إلى عدد الأعضاء الحاضرين وتعتبر القرارات جارية، ويتبع نظام



ما يثير انتباهنا هنا هو أنتا نجد خلطا في مسألة القرارات التي تصدر إثر

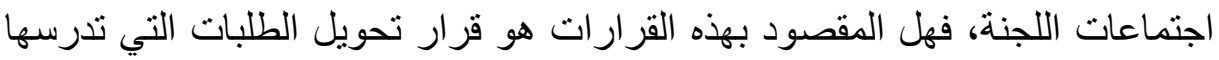

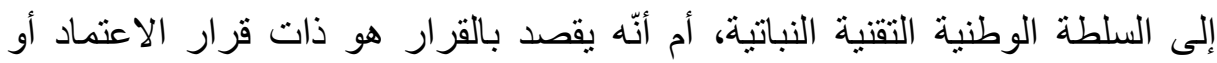
الترخيص الذي تتخذه السلطة الوطنية التقنية النباتية.

و إذا سلمنا بهذه الحالة الثانية، يعني أنّ هذه اللجنة هي الجهاز الإداري ومصدر التهاري

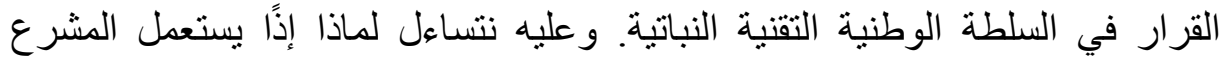

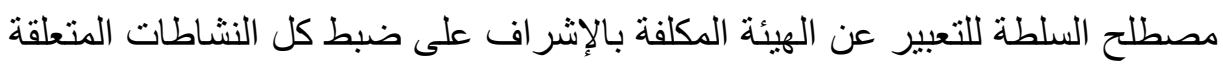
بالبذور و الثتائل و الحيازة النباتية، و المكلفة بمنح الاعتماد و التر اخيص في المئة المسألة. ثمّ يستعمل مصطلح اللجنة للتعبير عن الهيئة المكلفة بدراسة الطلبات المتعلقة بمنح

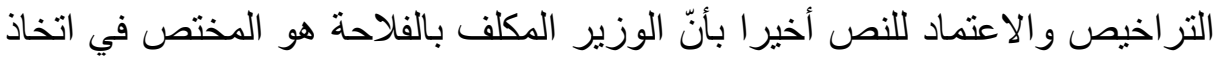

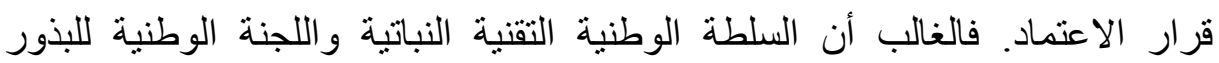
و الثتائل هيئتان مختلفتان، بل أنّ الهيئة الثانية من مكونات الهات الهيئة الأولى. وفي انتظار

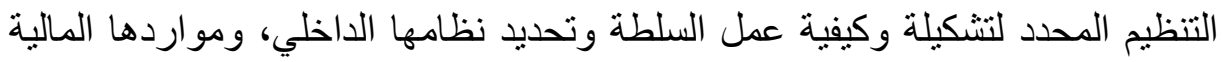
يقى الغموض في تحديد مركز ها القانوني قائما. 
خاتمة:

إنّ المشرع بخصوص السلطة الوطنية التقنية النباتية لم يكن و اضحا وصريحا

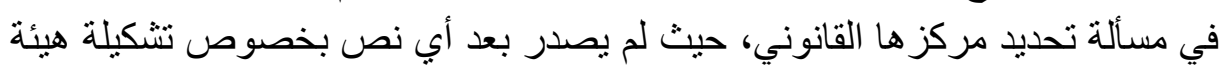

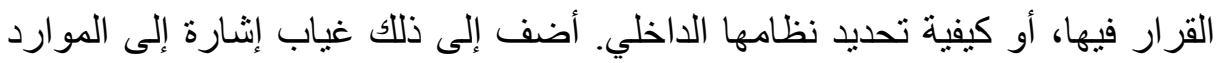
المالية للسلطة، علما أنّ الجانب المالي له أهميته في تحديد استقلالية السلطة. كلها عوامل تزيد من إضفاء صفة التبعية على هذه السلطة التي نكيفها على أنّها تفريع إداري لإدارة مركزية لا غير، ونص المادتين 05 و06 من المرسوم التنفيذي رقم

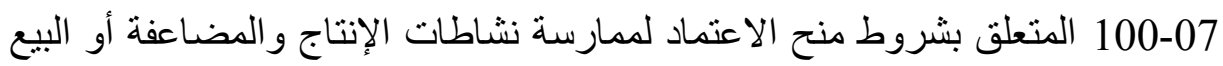

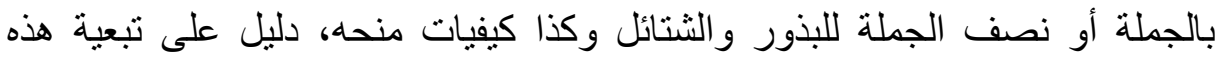

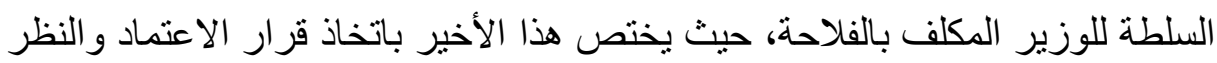

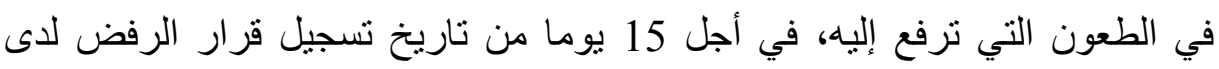
السلطة الوطنية التقنية النباتية. 
1 - راجع بهذا الصدد: آيت وازو زاينة، در اسة نقدية في سلطات الضبط المستقلة ، مداخلة في الملتقى الوطني حول سلطات الضبط المستقلة في المجال الاقتصادي و المالي، جامعة عبد الرحمن ميرة، أيام 23 - 24 ماي .2007

GELARD Patrice, Rapport sur les autorités administratives -2 indépendantes ?, in file : //H : N 3166-tl, Le 25/01/2008, p 26. voir aussi: DREYFES J. D, Pourquoi les autorités administratives indépendantes? Approche phénoménologique, in BOULOC B., (S/dire), "Autorités de régulation et vie des affaires", Dalloz, Paris, 2006.

ZOUAIMIA Rachid, "Droit e la régulation économique", p 124. ${ }^{3}$ 4ـ راجع المواد 04 و 05 من القانون رقم 05-03 المؤرخ في 2005/02/06، المتعلق بالبذور و الثتائل وحماية الحيازة النباتية، الجريدة الرسمية رقم رقان

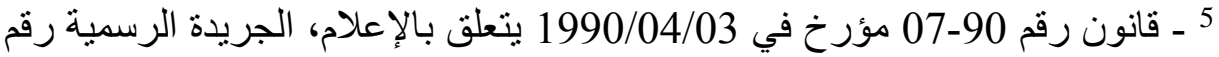

1990./14

6 ـ قانون رقم 06-01 مؤرخ في 20 فيفري 2006 يتعلق بالوقاية من الفساد ومكافحته، الفئ.


2006/11/22 يحدد تشكيلة تنظيم واختصاصات الجهاز الوطني للوقاية من الفساد

$$
\text { ومكافحته، الجريدة الرسمية رقم }
$$

7 ـ قانون رقم 2001-01 مؤرخ في 2001/07/03 معدل ومتمم يتضمن رفم القانون المنجمي، الجريدة الرسمية رقم 8ـ قانون رقم 205-12 مؤرخ في 2005/08/04 معدل ومتمم يتعلق بالمياه.


بواسطة القنوات، الجريدة الرسمية رقم 10ـ مرسوم تشريعي رقم 10-93 مؤرخ في 23 ماي 1993 ينعلق بيورصة القيم القيم

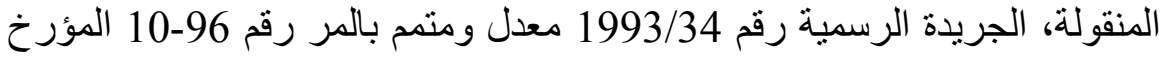


المؤرخ في 2003/02/17، الجريدة الرسمية رقم 11 ـ قانون رقم 2000-03 مؤرخ في 05 أوت 2000 يحدة 2003 يحد القو اعد المتعلقة بالبريد وبالمو اصلات السلكية و اللاسلكية، الجريدة الرسمية رقم


1995/09 و القانون رقم 03-03 المؤرخ في 2003/07/19، يتعلق بالمنافسة،

$$
\text { 2003.43 الجريدة الرسمية رقم }
$$

Pour de plus amples information voir : ZOUAIMIA Rachid, - 13 op.cit, p 123. 14ـ نص المادة 26 من قانون رقم 05-03 يتعلق بالبذور والثتائل وحماية الحيازة 


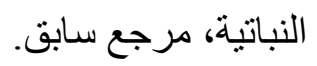

15 ـ المادة 34 من القانون رقم 05-03 يتعلق بالبذور و الثتائل وحماية الحيازة النباتية،



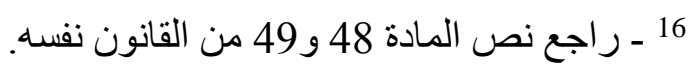

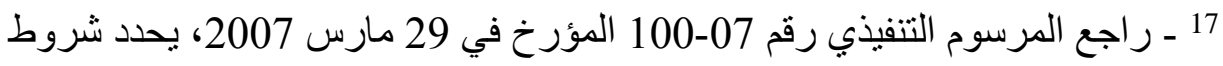


الجملة للبذور والثتائل، وكذا كيفيات الحصول النتاجة عليه، الجريدة الرسمية رقم 2007./22

18 ـ المواد 43، 49، 51 و و52 من القانون رقم 05-03 المتعلق بالبذور والثتائل و الحيازة النباتية، مرجع سابق.

19 ـ المادتين 62 و63 من القانون رقم 05-03 المنعلق بالبذور والثتائل والحيازة

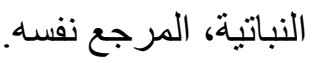

20 ـ المواد 64 و65 من القانون رقم 05-03 المتعلق بالذذور و الثتائل والحيازة



21 ـ مرسوم تنفيذي رقم تثكيلة وعمل اللجنة الوطنية للبذور و الثتائل، الجريدة الرسمية رقم

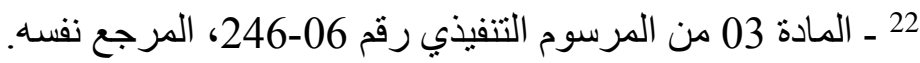
23 ـ المادة 22 من المرسوم التنفيذي نفسه. 